\title{
Regulated Shedding of Syndecan Ectodomains by Chemokines
}

\author{
Nathalie Charnaux ${ }^{1,2}$, Angela Sutton ${ }^{1}$, Severine Brule ${ }^{1}$, \\ and Liliane Gattegno ${ }^{1,2, *}$ \\ ${ }^{1}$ EA 3410, UFR SMBH - Université Paris 13, 74 rue Marcel Cachin, \\ 93017 Bobigny Cedex, France; ${ }^{2}$ Laboratoire de Biochimie, Hôpital \\ Jean Verdier, AP-HP, 93143 Bondy Cedex, France \\ E-mail: liliane.gattegno@jur.aphp.fr
}

Received July 5, 2006; Revised August 7, 2006; Accepted August 14, 2006; Published August 25, 2006

KEYWORDS: chemokine, SDF-1/CXCL12, syndecan, heparan sulfate proteoglycan, shedding

Chemokines are chemotactic cytokines that govern multiple aspects of host defense[1]. Interest in chemokines has increased as a result of their emerging role in immune and inflammatory responses, hematopoeisis, HIV infection[2,3,4], cancer cell proliferation, and migration[5]. Chemokines mediate biological activities through activation of G-protein-coupled receptors (GPCRs)[6]; however, they also bind to glycosaminoglycans (GAGs)[7,8,9], especially heparan sulfate (HS)[10]. GAGs are long, linear, and heterogeneous sulfated polysaccharides that are generally closely associated with or immobilized on cell surfaces by attachment to protein cores, forming proteoglycans (PGs)[11]. Four chemokine subgroups have been named $\mathrm{C}, \mathrm{CC}, \mathrm{CXC}$, or $\mathrm{CX}_{3} \mathrm{C}$ according to the number and spacing of cysteine residues[1]. Stromal cell-derived factor-1 (SDF-1/CXCL12), a CXC chemokine, constitutively expressed in a wide variety of tissues, binds to the GPCR CXCR4[6,12,13]. CXCR4 also functions as a coreceptor for X4 HIV isolates[14] and SDF-1/CXCL12 blocks cellular entry of these isolates[4,14]. Optimal inhibition requires SDF-1 interaction with cell surface HS[15]. However, the SDF-1/CXCL12-CXCR4 axis is involved in other pathological processes: angiogenesis, invasiveness, migration, and proliferation of cancer cells[16,17]. Nevertheless, the pathophysiological roles of chemokine-GAG interactions have not yet been elucidated.

In one of our recent works published in Glycobiology, we characterized the cell PG that binds to SDF-1/CXCL12[18]. The syndecans are a PG family, which together with the lipid-linked glypicans, are the major source of cell surface HS[11]. By way of their HS chains, syndecans bind a wide variety of ligands[11]. These PGs were also identified as HIV attachment receptors[19]. In this context, we showed that SDF-1/CXCL12 forms complexes on the human epidermoid carcinoma HeLa cell line, and on human primary lymphocytes and monocyte-derived macrophages (MDM), which comprise CXCR4 as expected and syndecan-4 (SDC-4), but not other PGs, syndecan-1 (SDC-1), CD44, nor betaglycan[18]. We also demonstrated that while SDC-4 and CXCR4 form a heteromeric complex on these cells, SDF-1/CXCL12 directly binds SDC-4 in a GAG-dependent manner. This suggests that SDF-1/CXCL12 may specifically bind a GAG structure present on SDC-4. However, this does not exclude that SDF-1/CXCL12 may also interact with some domains of the protein core of SDC-4. Moreover, in another recent paper published in FEBS Journal, we showed that SDC-4 behaves as a specific SDF-1/CXCL12 receptor, involved in SDF1/CXCL12-induced transduction pathways. By specifically reducing SDC-4 expression using RNA 
interference, we demonstrated that Erk1/2 and JNK/SAPK MAPK activation by SDF-1/CXCL12 requires SDC-4 expression. Moreover, SDF-1/CXCL12 induces the phosphorylation of its GPCR, CXCR4, and also that of SDC-4[20].

Shed syndecan ectodomains are newly defined mediators of inflammation that may be involved in cell proliferation and in several regulatory processes[21,22]. It was shown that matrix metalloproteinases (MMPs) are involved in syndecan shedding and catabolic processes of syndecans[23,24]. MMPs are secreted as latent enzymes and require proteolytic cleavage for activation. Chemokine stimulation of cell MMPs have been described. For instance, SDF-1/CXCL12 stimulates the production of MMP-9 by murine RAW cells[25]. We have consequently investigated whether SDF-1/CXCL12 accelerates the shedding of PG ectodomains from human cell lines and primary cells, and tried to elucidate which transduction pathways and protease(s) are involved and whether SDF-1/CXCL12 forms complexes with the shed ectodomains of PGs.

In a recent study published in Glycobiology[26], we demonstrated that SDF-1/CXCL12 accelerates the shedding of SDC-4 and, to a lesser extent, that of SDC-1 from HeLa cells and MDM (Fig. 1). Syndecan shedding accelerated by SDF-1/CXCL12 depends on cell surface HS chains, since it was abolished in heparitinase-treated cells, but does not depend on CXCR4 expression, as CXCR4 silencing by RNA interference had no effect. However, this SDF-1/CXCL12-induced shedding depends on a PKC transduction pathway because it was inhibited by a PKC inhibitor. In this context, we showed that SDF1/CXCL12 increases MMP-9 mRNA level and MMP-9 activity in HeLa cells, and that MMP-9 silencing by RNA interference strongly decreases SDC-1 and SDC-4 ectodomain shedding accelerated by SDF1/CXCL12. Moreover, the shedding of SDC-1 and SDC-4 accelerated by SDF-1/CXCL12 from MDM was significantly inhibited by anti-MMP-9 antibodies. Therefore, MMP-9 is involved in the accelerated shedding of syndecans induced by SDF-1 in both a tumoral cell line and in human primary macrophages. However, the fact that the accelerated shedding of SDC-1 was not decreased in MMP-9-deficient mice during allergic lung infection[27] suggests that different shedding sites may be used in this PG according to the chemokine, in a tissue-dependent manner, and also possibly in a disease-specific manner. Strikingly, immunoprecipitation experiments showed us that while SDF-1/CXCL12 binds to membraneanchored SDC-4, it does not bind to SDC-1 or SDC-4 ectodomains shed from HeLa cells. Therefore, membrane association of SDC-4 may well be critical for its interaction with SDF-1/CXCL12. In addition, the high density of SDC-4 and cell surface association may induce particular GAG chain orientation leading to optimal SDF-1/CXCL12 binding.
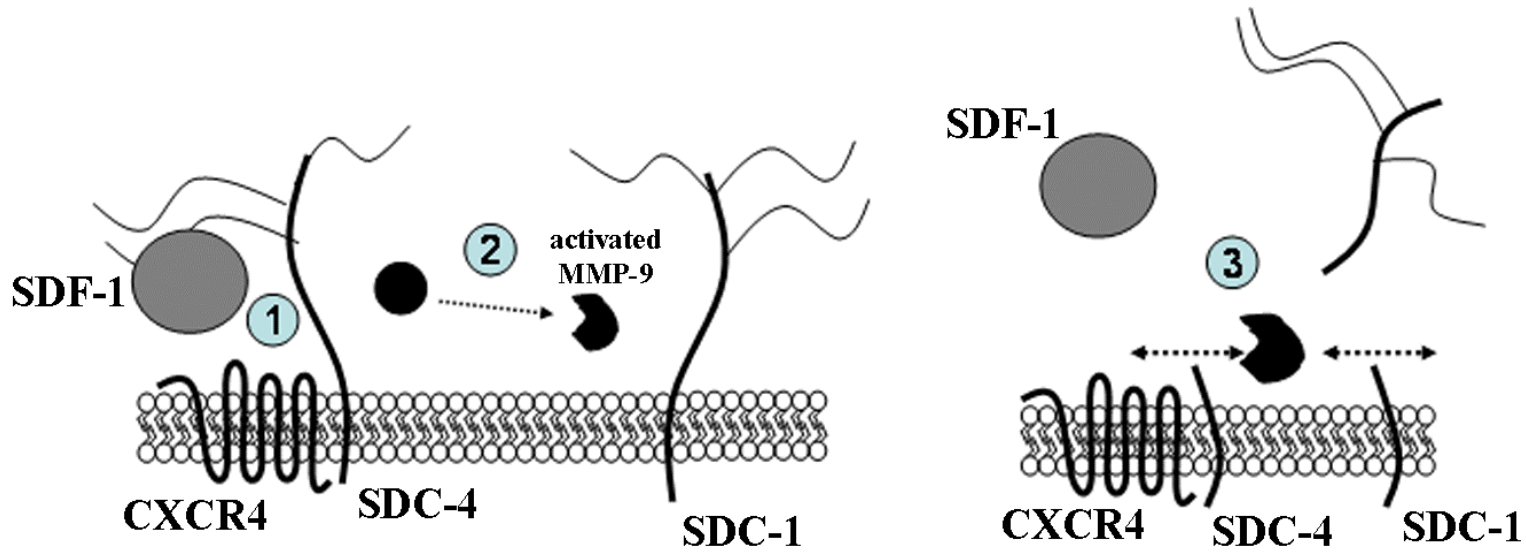

FIGURE 1. The shedding of SDC-4 and SDC-1 from HeLa cells and human primary macrophages is accelerated by SDF-1/CXCL12 and mediated by MMP-9. (1) SDF-1 binding to SDC-4 facilitates its presentation to CXCR4; (2) SDF-1 activates MMP-9, which is involved in syndecan shedding; (3) decreased membrane expression of syndecans down-regulates SDF-1 binding to the cells. 
In summary, our data strongly indicate that the shedding of SDC-4 and SDC-1 accelerated by SDF1/CXCL12 from human epidermoid carcinoma cells and from human primary macrophages is mediated by MMP-9. Considering that in our experiments, syndecan shedding accelerated by SDF-1/CXCL12 is associated with decreased syndecan membrane expression, as assessed by cytofluorimetric analysis after specific labeling, and that SDF-1/CXCL12 does not bind to soluble syndecan ectodomain, the role of syndecan shedding in the biological effect of SDF-1 may then be related to changes in the target cell surface phenotype rather than to a competitive inhibition in the binding of the chemokine to the target cell surface. In fact, one can speculate that SDC-4 shedding induced by SDF-1 /CXCL12 and mediated by MMP-9 could be part of an autoregulatory/down-regulation cycle: (1) SDF-1/CXCL12 binding to SDC-4 facilitates its presentation to CXCR4; (2) SDC-4 is a signaling molecule for SDF-1/CXCL12; (3) while SDF-1 accelerates SDC-4 ectodomain shedding, this chemokine decreases SDC-4 membrane expression. Therefore, SDF-1/CXCL12 down-regulates the cell plasma membrane expression of its coreceptor, the SDC-4. Interestingly, we recently demonstrated that RANTES/CCL5 (1) accelerates the shedding of SDC-1 and SDC-4 from HeLa cells, which depends on CCR5 and on both Erk1/2 MAPK and PKC transduction pathways; and (2) forms GAG-dependent complexes with the shed ectodomains of these PGs[28]. In addition, Xu et al. showed that SDC-1 ectodomains bind to CCL-7, -11, and -17 during lung inflammation[27]. Therefore, the respective molecular events involved in the acceleration of shedding of PGs induced by RANTES/CCL5 or SDF-1/CXCL12 differ according to the chemokine. Moreover, the binding capability of chemokines to shed syndecan ectodomains differs. For instance, RANTES/CCL5 and SDF-1/CXCL12, respectively, CC- and CXC-chemokines, are quite different. They show different GAG-binding epitopes and different quaternary structure (dimeric and oligomeric states)[29]. They also exhibit different expression patterns. RANTES is preferentially secreted during inflammatory process, whereas SDF-1/CXCL12 is constitutively expressed in various cell types and may play a "homeostatic" role. Therefore, SDC-1 and SDC-4 shedding accelerated by RANTES/CCL5 could be expected to occur during inflammatory and wound repair processes, whereas PG shedding accelerated by SDF-1/CXCL12 could occur even in the absence of any tissue injury. This accelerated shedding by chemokines may, therefore, represent fine regulatory mechanisms of chemokine activity in physiology and diseases.

\section{ACKNOWLEDGMENTS}

This work was supported by the Direction de la Recherche et des Enseignements Doctoraux (Ministère de l’Enseignement Supérieur et de la Recherche), Université Paris XIII.

\section{REFERENCES}

1. $\quad$ Luster, A.D. (1998) Chemokines--chemotactic cytokines that mediate inflammation. N. Engl. J. Med. 338, $436-445$.

2. Baggiolini, M., Dewald, B., and Moser, B. (1997) Human chemokines: an update. Annu. Rev. Immunol. 15, 675-705.

3. Ward, S.G., Bacon, K., and Westwick, J. (1998) Chemokines and T lymphocytes: more than an attraction. Immunity 9, 1-11.

4. $\quad$ Bleul, C.C., Wu, L., Hoxie, J.A., Springer, T.A., and Mackay, C.R. (1997) The HIV coreceptors CXCR4 and CCR5 are differentially expressed and regulated on human T lymphocytes. Proc. Natl. Acad. Sci. U. S. A. 94, 1925-1930.

5. Strieter, R.M. (2001) Chemokines: not just leukocyte chemoattractants in the promotion of cancer. Nat. Immunol. 2, 285-286.

6. Schwarz, M.S. and Wells, T.N. (1999) Interfering with chemokine networks-the hope for new therapeutics. Curr. Opin. Chem. Biol. 3, 407-417.

7. Hoogewerf, A.J., Kuschert, G.S., Proudfoot, A.E., Borlat, F., Clark-Lewis, I., Power, C.A., and Wells, T.N. (1997) Glycosaminoglycans mediate cell surface oligomerization of chemokines. Biochemistry 36, 13570-13578.

8. Lortat-Jacob, H., Grosdidier, A., and Imberty, A. (2002) Structural diversity of heparan sulfate binding domains in chemokines. Proc. Natl. Acad. Sci. U. S. A. 99, 1229-1234.

9. Martin, L., Blanpain, C., Garnier, P., Wittamer, V., Parmentier, M., and Vita, C. (2001) Structural and functional analysis of the RANTES-glycosaminoglycans interactions. Biochemistry 40, 6303-6318.

10. Sadir, R., Baleux, F., Grosdidier, A., Imberty, A., and Lortat-Jacob, H. (2001) Characterization of the stromal cell- 
derived factor-1alpha-heparin complex J. Biol. Chem. 276, 8288-8296.

11. Bernfield, M., Gotte, M., Park, P.W., Reizes, O., Fitzgerald, M.L., Lincecum, J., and Zako, M. (1999) Functions of cell surface heparan sulfate proteoglycans. Annu. Rev. Biochem. 68, 729-777.

12. Coulomb-L'Hermin, A., Amara, A., Schiff, C., Durand-Gasselin, I., Foussat, A., Delaunay, T., Chaouat, G., Capron, F., Ledee, N., Galanaud, P., Arenzana-Seisdedos, F., and Emilie, D. (1999) Stromal cell-derived factor-1 (SDF-1) and antenatal human B cell lymphopoiesis: expression of SDF-1 by mesothelial cells and biliary ductal plate epithelial cells. Proc. Natl. Acad. Sci. U. S. A. 96, 8585-8590.

13. Pablos, J.L., Amara, A., Bouloc, A., Santiago, B., Caruz, A., Galindo, M., Delaunay, T., Virelizier, J.L., and Arenzana-Seisdedos, F. (1999) Stromal-cell derived factor is expressed by dendritic cells and endothelium in human skin. Am. J. Pathol. 155, 1577-1586.

14. Oberlin, E., Amara, A., Bachelerie, F., Bessia, C., Virelizier, J.L., Arenzana-Seisdedos, F., Schwartz, O., Heard, J.M., Clark-Lewis, I., Legler, D.F., Loetscher, M., Baggiolini, M., and Moser, B. (1996) The CXC chemokine SDF-1 is the ligand for LESTR/fusin and prevents infection by T-cell-line-adapted HIV-1. Nature 382, 833-835.

15. Valenzuela-Fernandez, A., Palanche, T., Amara, A., Magerus, A., Altmeyer, R., Delaunay, T., Virelizier, J.L., Baleux, F., Galzi, J.L., and Arenzana-Seisdedos, F. (2001) Optimal inhibition of X4 HIV isolates by the CXC chemokine stromal cell-derived factor-1alpha requires interaction with cell surface heparan sulfate proteoglycans. $J$. Biol. Chem. 276, 26550-26558.

16. Geminder, H., Sagi-Assif, O., Goldberg, L., Meshel, T., Rechavi, G., Witz, I.P., and Ben-Baruch, A. (2001) A possible role for CXCR4 and its ligand, the CXC chemokine stromal cell-derived factor-1, in the development of bone marrow metastases in neuroblastoma. J. Immunol. 167, 4747-4757.

17. Kryczek, I., Lange, A., Mottram, P., Alvarez, X., Cheng, P., Hogan, M., Moons, L., Wei, S., Zou, L., Machelon, V., Emilie, D., Terrassa, M., Lackner, A., Curiel, T.J., Carmeliet, P., and Zou, W. (2005) CXCL12 and vascular endothelial growth factor synergistically induce neoangiogenesis in human ovarian cancers. Cancer Res. 65, 465-472.

18. Hamon, M., Mbemba, E., Charnaux, N., Slimani, H., Brule, S., Saffar, L., Vassy, R., Prost, C., Lievre, N., Starzec, A., and Gattegno, L. (2004) A syndecan-4/CXCR4 complex expressed on human primary lymphocytes and macrophages and HeLa cell line binds the CXC chemokine stromal cell-derived factor-1 (SDF-1). Glycobiology 14, 311-323.

19. Saphire, A.C., Bobardt, M.D., Zhang, Z., David, G., and Gallay, P.A. (2001) Syndecans serve as attachment receptors for human immunodeficiency virus type 1 on macrophages. J. Virol. 75, 9187-9200.

20. Charnaux, N., Brule, S., Hamon, M., Chaigneau, T., Saffar, L., Prost, C., Lievre, N., and Gattegno, L. (2005) Syndecan-4 is a signalling molecule for stromal derived-cell factor-1 (SDF-1)/CXCL12. FEBS J. 272, 1937-1951.

21. Fitzgerald, M.L., Wang, Z., Park, P.W., Murphy, G., and Bernfield, M. (2000) Shedding of syndecan-1 and -4 ectodomains is regulated by multiple signaling pathways and mediated by a TIMP-3-sensitive metalloproteinase. $J$. Cell Biol. 148, 811-824.

22. Gotte, M. (2003) Syndecans in inflammation. FASEB J. 17, 575-591.

23. Li, Q., Park, P.W., Wilson, C.L., and Parks, W.C. (2002) Matrilysin shedding of syndecan-1 regulates chemokine mobilization and transepithelial efflux of neutrophils in acute lung injury. Cell 111, 635-646.

24. Endo, K., Takino, T., Miyamori, H., Kinsen, H., Yoshizaki, T., Furukawa, M., and Sato, H. (2003) Cleavage of syndecan-1 by membrane type matrix metalloproteinase-1 stimulates cell migration. J. Biol. Chem. 278, 4076440770.

25. Yu, X., Huang, Y., Collin-Osdoby, P., and Osdoby, P. (2003) Stromal cell-derived factor-1 (SDF-1) recruits osteoclast precursors by inducing chemotaxis, matrix metalloproteinase-9 (MMP-9) activity, and collagen transmigration. J. Bone Miner. Res. 18, 1404-1418.

26. Brule, S., Charnaux, N., Sutton, A., Ledoux, D., Chaigneau, T., Saffar, L., and Gattegno, L. (2006) The shedding of syndecan-4 and syndecan-1 from HeLa cells and human primary macrophages is accelerated by SDF-1/CXCL12 and mediated by the matrix metalloproteinase-9. Glycobiology 16, 488-501.

27. Xu, J., Park, P.W., Kheradmand, F., and Corry, D.B. (2005) Endogenous attenuation of allergic lung inflammation by syndecan-1. J. Immunol. 174, 5758-5765.

28. Charnaux, N., Brule, S., Chaigneau, T., Saffar, L., Sutton, A., Hamon, M., Prost, C., Lievre, N., Vita, C., and Gattegno, L. (2005) RANTES (CCL5) induces a CCR5-dependent accelerated shedding of syndecan-1 (CD138) and syndecan-4 from HeLa cells and forms complexes with the shed ectodomains of these proteoglycans as well as with those of CD44. Glycobiology 15, 119-130.

29. Handel, T.M., Johnson, Z., Crown, S.E., Lau, E.K., Sweeney, M., and Proudfoot, A.E. (2005) Regulation of protein function by glycosaminoglycans - as exemplified by chemokines. Annu. Rev. Biochem. 74, 385-410.

\section{This article should be cited as follows:}

Charnaux, N., Sutton, A., Brule, S., and Gattegno, L. (2006) Regulated shedding of syndecan ectodomains by chemokines. TheScientificWorldJOURNAL 6, 1037-1040. DOI 10.1100/tsw.2006.201. 

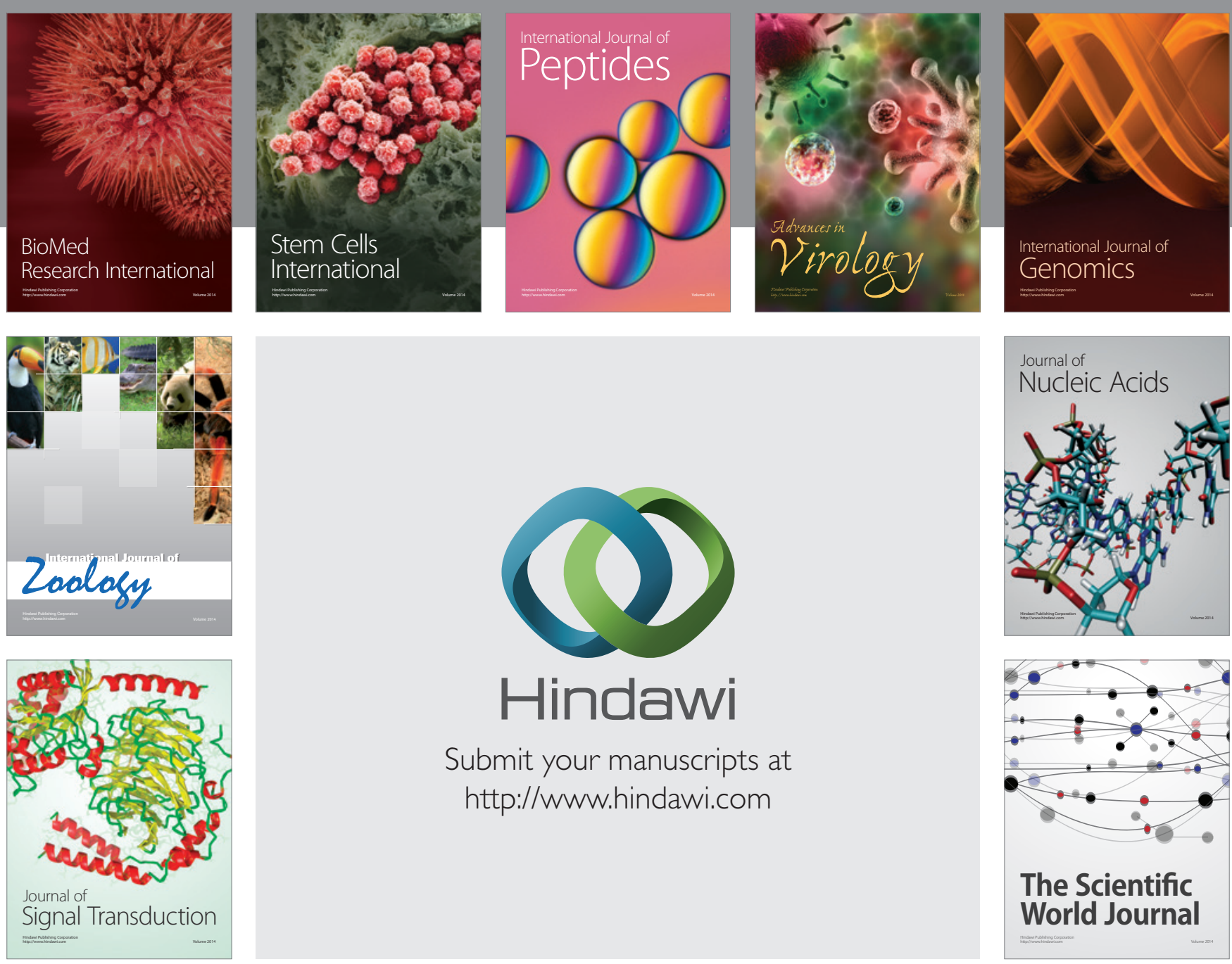

Submit your manuscripts at

http://www.hindawi.com
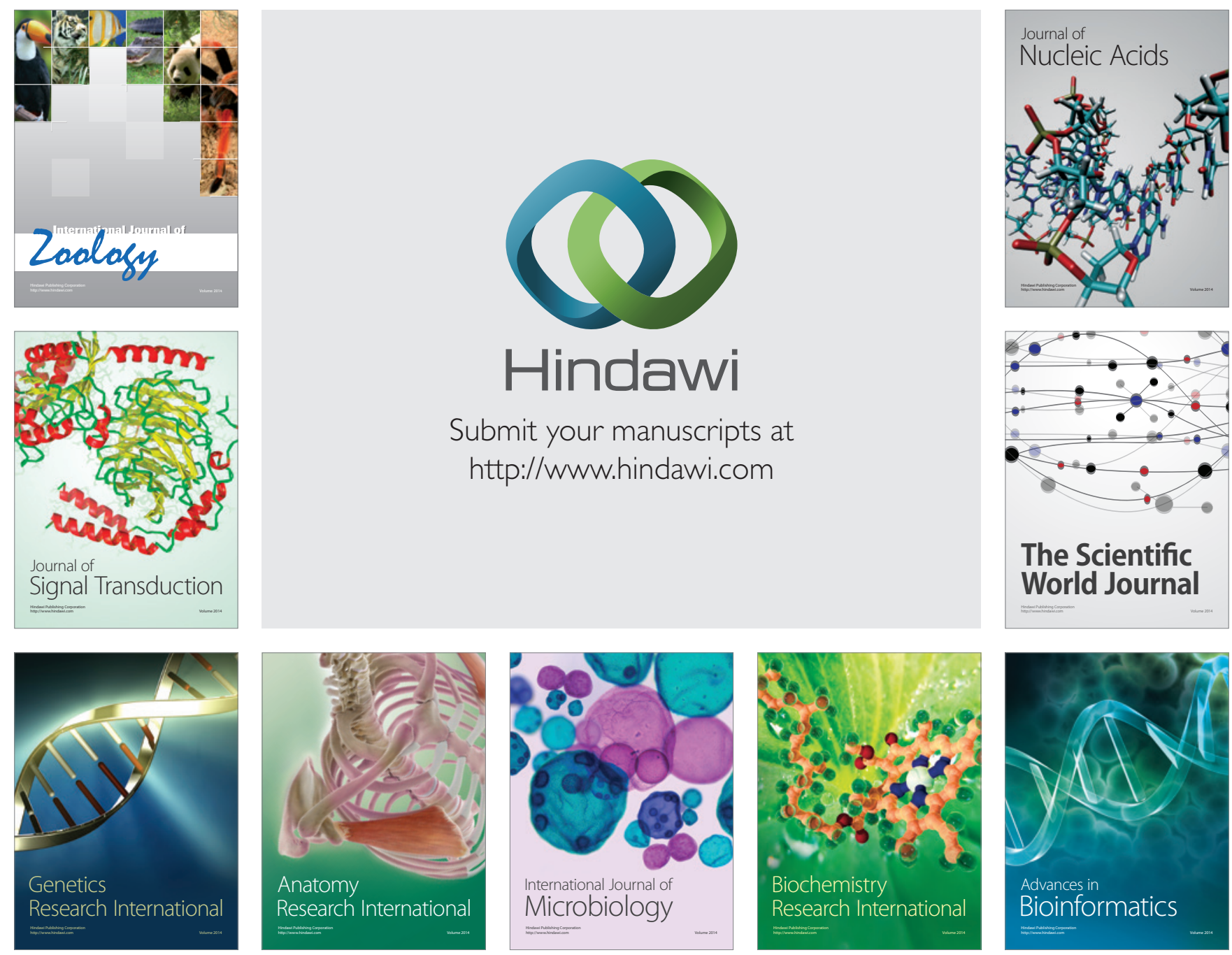

The Scientific World Journal
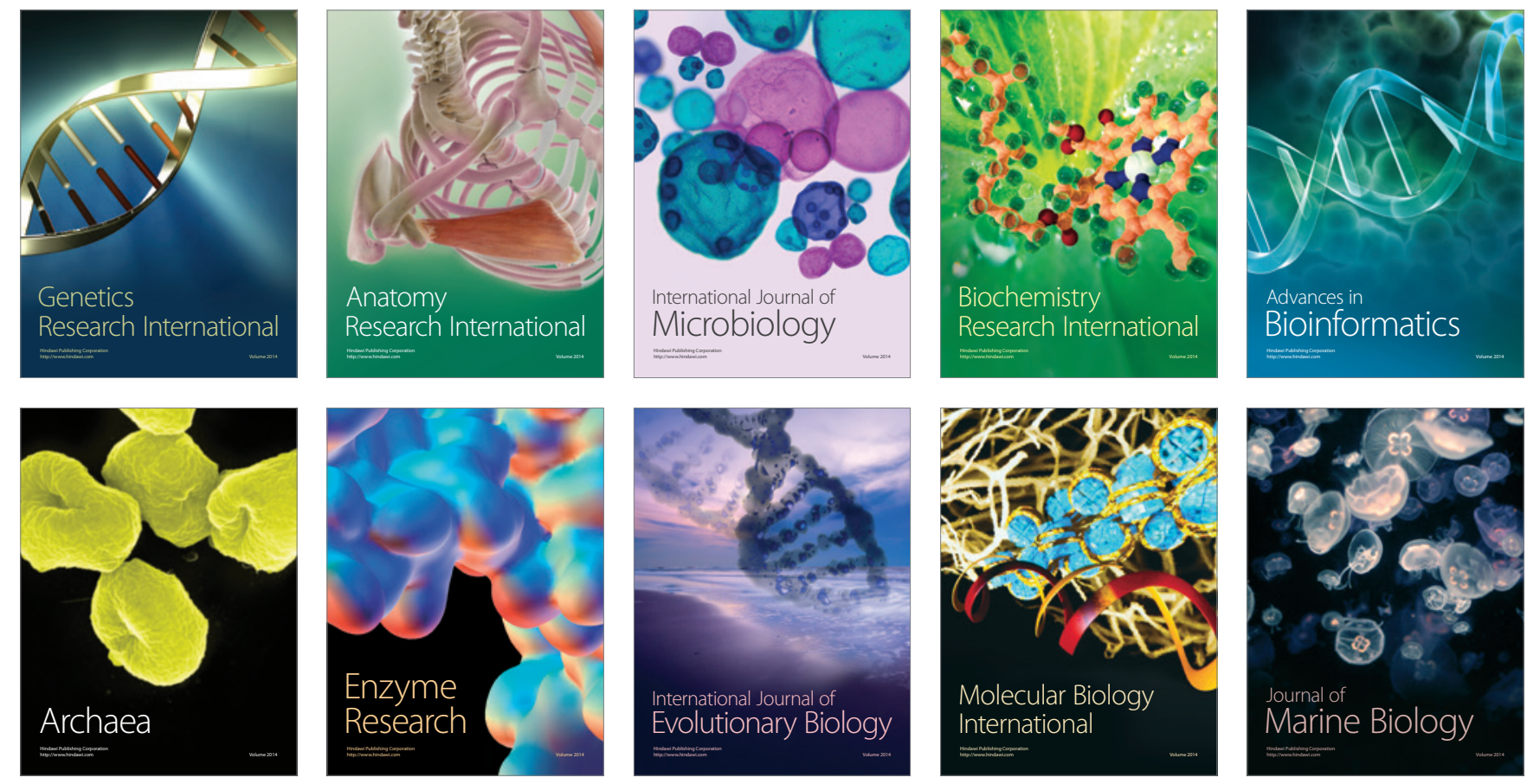